\title{
Effects of Atypical Neuroleptics on Sustained Attention Deficits in Schizophrenia: A Trial of Risperidone Versus Haloperidol
}

Shi K. Liu, M.D., Wei J. Chen, M.D., Sc.D., Ching-Jui Chang, M.D., and Hsin-Nan Lin, M.D.

To help determine whether sustained attention deficits as measured with the Continuous Performance Test (CPT) are stable vulnerability indicators of schizophrenia, we compared the CPT performance of schizophrenic patients before and after treatment with risperidone or haloperidol. In this double blind trial, 56 schizophrenic patients were randomly assigned to a 12-week regimen of either risperidone or haloperidol, after a 1-week washout period. The patients undertook two sessions of the CPT (undegraded and $25 \%$ degraded) twice, one at the end of the washout period and the other at the end of the study. Thirty- eight patients completed the study, 19 in each group. Both groups experienced significant improvements in clinical symptoms, and the risperidone group showed no change in the severity of extrapyramidal symptoms. Despite those improvements, the CPT performance indexes did not change significantly from the beginning to the end of the study. These findings indicate that sustained attention deficits might be stable vulnerability indicators of schizophrenia. [Neuropsychopharmacology 22: 311-319, 2000] (c) 2000 American College of Neuropsychopharmacology. Published by Elsevier Science Inc.
KEY WORDS: Continuous Performance Test (CPT); Double blind; Extrapyramidal side effects; Haloperidol;

Risperidone; Vulnerability indicator

The Continuous Performance Test (CPT) (Rosvold et al. 1956) consistently demonstrates sustained attention deficits in schizophrenic patients (Nuechterlein 1991). Early cross-sectional studies have reported that schizophrenic patients exhibit CPT performance deficits whether they are chronically hospitalized (Orzack and Kornetsky 1966) or in remission (Asarnow and MacCrimmon 1978; Wohlberg and Kornetsky 1973), in comparison with normal controls. The deficits are relatively specific for schizophrenia as compared to other psychi-

From the Department of Psychiatry, College of Medicine (SKL; CJC; HNL) and the Institute of Epidemiology, College of Public Health (WJC), National Taiwan University, Taipei, Taiwan; and the Department of Psychiatry, Cathay General Hospital (CJC), Taipei, Taiwan.

Address correspondence to: Dr. Wei J. Chen, MD, ScD, Institute of Epidemiology, College of Public Health, National Taiwan University, 1 Jen-Ai Road Sec.1, Taipei 100, Taiwan.

Received October 30, 1998; revised October 11, 1999; accepted October 17, 1999. atric disorders (Cornblatt et al. 1989; Mussgay and Hertwig 1990). Similar deficits on CPT performance have also been demonstrated in populations at increased risk for schizophrenia, such as those with schizotypal personality disorders (Harvey et al. 1996), relatives of schizophrenic patients (Chen et al. 1998b; Mirsky et al. 1995; Rutschmann et al. 1977), and nonclinical subjects with high schizotypy scores (Chen et al. 1998a; Lenzenweger et al. 1991). All these characteristics indicate that CPT performance deficits are potential endophenotypic indicators (i.e., behavioral characteristics that mark the presence of genotypic risk) of schizophrenia (Cornblatt and Keilp 1994).

Evidence regarding whether CPT performance deficits represent stable or mediating indicators of vulnerability to schizophrenia, however, is not yet conclusive. As Nuechterlein and Dawson (1984) have pointed out, if CPT performance is a mediating vulnerability indicator, schizophrenic patients' performance should be lower than that of the general population and become poorer during overt symptoms than during remission. 
If CPT performance is a stable vulnerability indicator, schizophrenic patients' performance should be lower than that of the general population and unrelated to changes in clinical symptoms. Thus, an improvement in CPT performance after effective neuroleptic treatment would indicate that attention deficits in schizophrenia represent mediating vulnerability indicators. In contrast, if attention deficits in schizophrenia represent stable vulnerability indicators, one would expect $\mathrm{CPT}$ performance to be unchanged after effective neuroleptic treatment. Orzack et al. (1967) have first reported that effective neuroleptic medication leads to improvement in both CPT performance and global symptoms in schizophrenic patients, and three subsequent studies with similar longitudinal designs that measured within-subject changes have reported similar findings (Mirsky et al. 1984; Nuechterlein et al. 1991; Spohn et al. 1977). However, four other longitudinal studies have failed to detect any change in CPT performance in schizophrenic patients in response to neuroleptics (Cornblatt et al. 1997; Epstein et al. 1996; Erickson et al. 1984; Finkelstein et al. 1997). Similarly, several crosssectional studies have found significant differences in CPT performance between patients who were receiving medication and those who were not (Earle-Boyer et al. 1991; Nestor et al. 1991; Orzack and Kornetsky 1971; Serper et al. 1990), while many others have failed to detect such differences (Harvey et al. 1990; Strandburg et al. 1990; Walker and Shaye 1982). This inconsistency has been partly explained on methodological grounds, including the compositions of the study samples, whether a normal control group was present, and the fact that the various CPT versions used have different perceptual and working memory loads (Nuechterlein et al. 1992). However, one has to note that in these studies patients all received traditional neuroleptics.

Evaluation of the effects of traditional neuroleptics on sustained attention in schizophrenia might be complicated by two features of these drugs. First, the intrinsic anticholinergic property of these neuroleptics and the frequent use of associated anticholinergic medications might affect patients' attentional processes (Bushnell et al. 1997). Second, the sedating effects and extrapyramidal side-effects (EPS) inducing properties of neuroleptics may compromise test performance (Brockel and Fowler 1995). An atypical neuroleptic with different receptor-binding profile and possibly different mode of therapeutic action might provide an opportunity to clarify this issue. The atypical neuroleptic risperidone exerts combined serotonin and dopamine antagonism (Leysen et al. 1994), and is practically devoid of anticholinergic effects and induces only minimal EPSs (Van Cauteren et al. 1996). Risperidone has been reported to improve both positive and negative symptoms, with fewer propensities to elicit psychomotor side effects (Carman et al. 1995; Peuskens 1995). In ad- dition, preliminary studies have suggested that risperidone might improve a variety of neurocognitive functions, including executive function as measured by Wisconsin Card Sorting Test (Rossi et al. 1997), sustained attention, delay visual recall and delayed verbal recall (Addington and Addington 1997). Thus, studies evaluating the effects of risperidone on CPT performance in schizophrenic patients might help determine whether sustained attention deficits are stable vulnerability indicators of schizophrenia.

In this study, we presented the results of a longitudinal, double-blind study comparing the effects of risperidone and haloperidol on sustained attention deficits in schizophrenic patients. The aims were to test whether schizophrenic patients' CPT performance is independent of their clinical state and to explore the potential therapeutic effects of risperidone on attention deficits in schizophrenic patients.

\section{MATERIALS AND SUBJECTS}

\section{Subjects}

The subjects of this study were part of a 12-week double-blind, parallel-group study on the therapeutic effects of risperidone versus haloperidol. The recruitment of subjects and the study design have been described in detail elsewhere (Liu et al. 1996). Briefly, 56 patients meeting the DSM-III-R (American Psychiatric Association 1987) criteria for schizophrenic disorders were recruited from the outpatient clinic or the acute inpatient ward of the Psychiatric Department, National Taiwan University Hospital. To be included, patients had to show prominent clinical symptoms as revealed by a total score of $>65$ on the Positive and Negative Syndrome Scale (PANSS) (Kay et al. 1987). The initial diagnoses were made by the principal investigator (S.K.L) using all available information, including data collected in clinical interviews based on the Chinese version of the Diagnostic Interview for Genetic Studies (DIGS) (Chen et al. 1998b; Nurnberger et al. 1994) and past medical records. The diagnoses were confirmed in a consensus meeting held by three senior psychiatrists. Patients with a previous history of physical illness or substance abuse that cast the diagnoses in doubt were excluded. All patients gave written informed consent to participate in this study. The study was approved by the Ethics Committee of National Taiwan University College of Medicine.

\section{Symptom-rating instruments}

The clinical symptoms of the patients were assessed with the PANSS, which has guidelines for a semi-structured interview with detailed descriptions of symptom ratings, and has been thoroughly studied psychometri- 
cally (Kay 1991). The PANSS consists of three subscales for separate syndromes: positive, negative, and general psychopathology. The severity of each syndrome is represented by the summed scores of the Positive (ranging from 7 to 49), Negative (ranging from 7 to 49), and General Psychopathology (ranging from 16 to 112) scales. The time period covered by each PANSS evaluation is one week prior to the date of clinical evaluation. A Chinese version of the PANSS, the PANSS- $\mathrm{CH}$, was translated from the English version and has been described in detail elsewhere (Cheng et al. 1996). Good interrater reliabilities on the PANSS-CH were achieved in a subsequent study of 30 schizophrenic patients, as revealed by the high intraclass correlation coefficient reliabilities for individual items (ranging from 0.64 to 0.96) (Liu et al. 1997).

The Extrapyramidal Symptom Rating Scale (ESRS) (Chouinard et al. 1980) was used to assess the severity of EPS. The ESRS consists of four subscales that assess subjective EPS, objectively observed parkinsonian symptoms, dystonia, and dyskinesia, respectively. In addition, two global scores for parkinsonism and dyskinesia were generated by global clinical impression. Because the slowing down of psychomotor activities associated with parkinsonism might affect the performances on attentional tasks, the summed score of the objectively observed parkinsonian symptom ratings (ESRS-P) and the global rating for parkinsonism (ESRS-GP) was used for the subsequent analyses. All raters using the ESRS viewed 30 sessions of videotaped examples of various involuntary movements with subsequent discussion for agreement about the ratings. Subsequent reliability exercises were done regularly at biweekly intervals to ensure agreement.

\section{CPT}

We used a CPT machine from Sunrise Systems, version 2.20 (Pembroke, MA, USA). The procedure has been described in detail elsewhere (Chen et al. 1998a; Liu et al. 1997). Briefly, numbers from 0 to 9 were randomly presented for 50 milliseconds each, at a rate of 1 per second. Each subject undertook two CPT sessions: the undegraded 1-9 task and the degraded 1-9 task. A total of 331 trials, 31 of them targets, were presented over a period of 5 minutes for each session. During the $25 \%$ degraded session, a pattern of snow was used to toggle the background and foreground dots so that the image was not distinct. The undegraded session was administered first and then the degraded session. Each session of the test began with 2 minutes of practice (repeated if subjects required it). The rater, who sat or stood at an oblique angle to the subject, could monitor the subject's performance through a computer monitor and make sure that the subject knew how to press the button correctly. Once a test began, no rewards or cues were given to the subject.
Two signal-detection indices, the sensitivity $\left(\mathrm{d}^{\prime}\right)$ and the response criterion $(\ln \beta)$, of CPT performance were derived from hits (probability of response to target trials) and false alarms (probability of response to nontarget trials) (Nuechterlein 1991). The sensitivity index ( $\left.\mathrm{d}^{\prime}\right)$ reflects the degree to which the frequency distribution of the internal perceptual evidence generated by signal trials is separated from that generated by nonsignal or noise trials, while the response criterion index $(\ln \beta)$ assesses the amount of perceptual evidence an individual requires prior to making a decision to respond to a stimulus as a signal. Variables extraneous to the intended comparison $\left(d^{\prime}\right)$, such as differences in motivation or in cooperativeness between the groups, would yield differences in the response criterion rather than in $\mathrm{d}^{\prime}$.

\section{Procedures}

After being enrolled in the study, all patients underwent a 1-week pretrial washout period of all previous antipsychotic medications. Adjuvant medications including benzodiazepine, beta-blocker, and anti-parkinsonian medications were allowed in some patients for additional 2 to 3 days, but all were discontinued at the end of the washout period. The initial evaluations were then performed while patients were in a drug-free state (baseline). The evaluations included a clinical interview with the PANSS-CH and ESRS, and an assessment of sustained attention with both the undegraded and the degraded CPT. The PANSS-CH and ESRS raters were blind to the results of the CPT.

After the initial evaluations were completed, the participating patients were randomly assigned to one of two treatment groups (risperidone or haloperidol) by means of a blocked randomization procedure, with a block size of 4 . The antipsychotic treatment lasted for a total of 12 weeks. During this period, clinical evaluations with the PANSS-CH and ESRS were performed in a double-blind manner at the end of the 1st, 2nd, 4th, 6th, 8th, and 12th weeks. In addition to the neuroleptics, adjuvant medications including trihexyhenidyl, lorazepam and propranolol were given on the basis of clinical judgement to relieve the side effects of neuroleptics. The dosage of the adjuvant medications was titrated carefully to be kept as low as possible. Once the side effects have been controlled, further reduction of dosage was attempted.

At endpoint (the end of 12th week), both sessions of the CPT were again administrated on the same day along with the final PANSS-CH and ESRS evaluations. Considering that discontinuing antipsychotic medications might have detrimental effects upon patients' clinical conditions, no attempt was made for a washout before the final evaluations. However, all adjuvant medications were discontinued 24 hours prior to the 
CPT tests. During this period, only two patients experienced mild insomnia, which could be relieved by single dose of placebo.

\section{Data Analysis}

Changes of scores from baseline to endpoint were assessed with paired t-tests. The scores of the patients receiving risperidone were compared with those of the patients receiving haloperidol by means of independent t-tests at both baseline and endpoint, respectively. Potential effects of type of neuroleptics, concurrent clinical symptoms, and EPS on CPT performance were assessed with multiple linear regression analyses. The baseline CPT indexes were regressed on treatment group, the baseline PANSS total score, and the baseline ESRS-P score. Similarly, the endpoint CPT indexes were regressed on treatment group, the endpoint PANSS total score, and the endpoint ESRS-P score. Because a previous study found that older age, female sex, and lower education level were associated with poorer CPT performance (Chen et al. 1998a), we standardized the patients' d' with adjustments for sex, age, and education as described by Chen et al. (1998b). Briefly, the d's were regressed on these covariates among the 345 community subjects reported in the previous study of Chen et al. (1998a). Adjusted scores of subjects were then calculated, using the regression coefficients for these covariates derived from the community subjects. The residual of the regression was then standardized by the root mean error of the regression, and was defined as the adjusted $\mathrm{z}$ score of $\mathrm{d}^{\prime}$. To further explore the relationship between baseline $d^{\prime}$ and the magnitude of improvements in $\mathrm{d}^{\prime}$, we calculated the proportional change in $\mathrm{d}^{\prime}$ $\left(\Delta \mathrm{d}^{\prime}\right)$ as (endpoint $\mathrm{d}^{\prime}$-baseline $\left.\mathrm{d}^{\prime}\right) /\left(\right.$ baseline $\left.\mathrm{d}^{\prime}\right)$. All statistical analyses were done with the Statistical Package for Social Sciences-PC (SPSS-PC) (Norusis 1986). A $p$ value of less than .05 (two-tailed) was considered statistically significant.

\section{RESULTS}

Of the 56 patients, 7 receiving risperidone and 9 receiving haloperidol dropped out of the trial. The drop-out rates did not differ significantly between the two groups $(p=0.6)$. Forty patients completed the 12-week trial, 21 in the risperidone group and 19 in the haloperidol group. Among them, 2 patients receiving risperidone did not complete the CPT at the end of the study and were excluded from subsequent analyses. Of the 38 patients who completed both the clinical evaluations and the two CPT sessions at baseline and endpoint, there were no significant differences in age, sex, education, or duration of illness between patients receiving risperidone and those receiving haloperidol (Table 1).
At baseline, both groups of patients were also similar in terms of severity of clinical symptoms as measured with the PANSS-CH and the severity of parkinsonism as measured with the ESRS (Table 2).

At endpoint, both groups showed significant reductions in the PANSS-CH scores (total, Positive, Negative, and General Psychopathology subscale) (Table 2), and the magnitudes of the reductions in the PANSS-CH scores were similar in the two groups. However, at endpoint, the haloperidol group had significantly higher ESRS-P scores than the risperidone group, despite having received adjuvant anti-parkinsonian medications. Overall, risperidone and haloperidol seemed to improve clinical symptoms equally well, while the latter induced more severe symptoms of parkinsonism.

The CPT performance of the schizophrenic patients was much poorer than that of the general population, as revealed by the negative adjusted $\mathrm{z}$ scores of $\mathrm{d}^{\prime}$ (Table 3). The performance on the degraded CPT was significantly lower than that on the undegraded CPT in both groups, both at baseline and at endpoint. The two groups had similar CPT performance scores at baseline except for the $\ln \beta$. At endpoint, however, the raw score and adjusted $\mathrm{z}$ score of the undegraded CPT $\mathrm{d}^{\prime}$ of the risperidone group were significantly higher than those of the haloperidol group $(t=2.07, d f=37, p=.05$, and $t=$ $2.00, d f=37, p=.05$, respectively). When considered longitudinally, none of the CPT indexes changed significantly from baseline to endpoint, in either group (Table 3 ).

The Pearson correlation between $\mathrm{d}^{\prime}$ and $\Delta \mathrm{d}^{\prime}$ was moderate $(r=0.35, n=38, p=.03)$ for the undegraded CPT but was unremarkable $(r=0.005, n=38, p=.98)$ for the degraded CPT. When the $\Delta \mathrm{d}^{\prime}$ 's of patients whose baseline adjusted $\mathrm{z}$ score of $\mathrm{d}^{\prime}$ in the upper $50 \%$ were compared with those of patients whose baseline adjusted z score of $\mathrm{d}^{\prime}$ in the lower $50 \%$ by independent $\mathrm{t}$-test, the difference was not significant for both the undegraded and degraded CPT.

When CPT indexes were regressed on the type of neuroleptics and the concurrent scores on the PANSS total scale and the ESRS-P, none of the independent variables could predict the CPT performances at both baseline and endpoint, respectively. Briefly, the linear regression models consisting of the three independent variables did not predict $\mathrm{d}^{\prime}$ at either baseline $(F=.60$, $d f=37, p=.62$ for the undegraded CPT, and $F=.69$, $d f=37, p=.57$ for the degraded CPT) or endpoint $(F=$ 1.36, $d f=37, p=.27$ for the undegraded CPT, and $F=$ $.20, d f=37, p=.89$ for the degraded CPT). Similarly, none of the three independent variables were associated with the other CPT performance indexes, either at baseline or at endpoint (data not shown).

To assess whether there were carry-over effects of the adjuvant medications on CPT performance at endpoint, a separate analysis was done on a subgroup of patients who received risperidone only, without any 
Table 1. Characteristics of Patients Receiving Risperidone or Haloperiodol

\begin{tabular}{lccc}
\hline Variable & $\begin{array}{c}\text { Risperidone } \\
\mathbf{( n = 1 9 )} \\
\text { Mean (SD) }\end{array}$ & $\begin{array}{c}\text { Haloperidol } \\
(\mathbf{n}=\mathbf{1 9 )} \\
\text { Mean (SD) }\end{array}$ & $\begin{array}{c}\text { Total } \\
(\mathbf{n}=38) \\
\text { Mean (SD) }\end{array}$ \\
\hline Male, n (\%) & $9(47)$ & $6(32)$ & $15(40)$ \\
Age (years) & $32.7(8.4)$ & $35.1(13.0)$ & $33.9(10.8)$ \\
Education (years) & $12.0(2.8)$ & $11.4(4.0)$ & $11.7(3.4)$ \\
Age at onset (years) & $25.5(7.8)$ & $26.6(11.4)$ & $26.5(9.6)$ \\
Duration of illness (years) & $7.3(5.4)$ & $8.4(8.2)$ & $7.8(6.8)$ \\
\hline
\end{tabular}

All between-group comparisons were not significant at the .05 level (two-tailed)

adjuvant medication during the entire study period $(n=10)$. Paired t-tests revealed that there was no significant change in all CPT indexes across time in these patients (e.g., for the undegraded CPT d', $t=-1.36, p=$ .12; for the degraded CPT d', $t=0.18, p=.86$; for the undegraded CPT $\ln \beta, t=.33, p=.75$; and for the degraded CPT $\ln \beta, t=-.38, p=.72 ;$ all $d f=9$ ).

\section{DISCUSSION}

To our knowledge, this is the first longitudinal and double-blind study examining the effects of risperidone on sustained attention deficits in schizophrenia. Although Addington and Addington (1997) reported that risperidone might improve sustained attention compared with haloperidol, the results are at best preliminary, considering its small sample size $(n=6)$. The results of the present study showed that sustained attention deficits in schizophrenic patients as assessed by both the undegraded and degraded CPT did not change significantly from baseline to the end of the 12week antipsychotic treatment with risperidone or haloperidol, despite significant reductions in symptom se- verity. This finding provided support for the proposition that CPT performance deficits might not be amendable by antipsychotic treatments. Several features of this study might make this finding unlikely to be confounded by the study design, the format of the $\mathrm{CPT}$, or coexisting psychiatric symptoms and EPS.

In assessing the effects of neuroleptics on CPT performance in schizophrenic patients, the use of a crosssectional design is problematic because of the possibility of marked variability in performance of the population. In addition, the effects of temporal fluctuations could not be adequately addressed, and this might partly account for the conflicting results of previous studies. In this regard, the present study had the merits that it was conducted with a sufficient interval between assessments to avoid practice effects (Epstein et al. 1996) and to assess within-subject changes in CPT performance across different states. Our finding that CPT performance is relatively independent of the severity of clinical symptoms is consistent with the most recently published studies using longitudinal designs with sufficient follow-up times and information processing paradigms (Cornblatt et al. 1997; Epstein et al. 1996; Finkelstein et al. 1997; Goldberg et al. 1993; Nuechterlein et al.

Table 2. Psychiatric and Parkinsonism Symptoms at Baseline and Endpoint of the Two Groups of Schizophrenic Patients

\begin{tabular}{|c|c|c|c|c|c|c|}
\hline \multirow[b]{2}{*}{ Symptom score } & \multicolumn{2}{|c|}{ Baseline } & \multicolumn{2}{|c|}{ Endpoint } & \multicolumn{2}{|c|}{ Change } \\
\hline & $\begin{array}{c}\text { Risperidone } \\
(\mathrm{n}=19) \\
\text { Mean (SD) }\end{array}$ & $\begin{array}{l}\text { Haloperidol } \\
(\mathrm{n}=19) \\
\text { Mean (SD) }\end{array}$ & $\begin{array}{c}\text { Risperidone } \\
(\mathrm{n}=19) \\
\text { Mean (SD) }\end{array}$ & $\begin{array}{l}\text { Haloperidol } \\
(\mathrm{n}=19) \\
\text { Mean (SD) }\end{array}$ & $\begin{array}{c}\text { Risperidone } \\
(\mathrm{n}=19) \\
\text { Mean (SD) }\end{array}$ & $\begin{array}{l}\text { Haloperidol } \\
(\mathrm{n}=19) \\
\text { Mean (SD) }\end{array}$ \\
\hline \multicolumn{7}{|l|}{ PANSS } \\
\hline Total & $76.0(16.1)$ & $86.1(14.9)$ & $51.3(18.5)$ & $54.5(16.3)$ & $-24.7(15.7)^{a}$ & $-31.6(20.6)^{a}$ \\
\hline Positive subscale & $21.1(5.4)$ & $23.6(6.5)$ & $12.3(6.7)$ & $13.7(6.5)$ & $-8.8(7.4)^{a}$ & $-9.7(7.3)^{a}$ \\
\hline Negative subscale & $18.3(7.2)$ & $20.3(7.5)$ & $12.9(4.8)$ & $14.3(4.6)$ & $-5.4(8.0)^{a}$ & $-5.4(8.0)^{a}$ \\
\hline $\begin{array}{l}\text { General psychopathology } \\
\text { subscale }\end{array}$ & $36.6(9.2)$ & $42.2(9.6)$ & $26.1(10.0)$ & $26.4(7.5)$ & $-10.5(7.3)^{a}$ & $-15.7(12.5)^{a}$ \\
\hline \multicolumn{7}{|l|}{ ESRS } \\
\hline ESRS-P & $2.7(4.4)$ & $1.5(2.6)$ & $2.4(2.5)$ & $4.1(5.0)^{b}$ & $-0.3(5.0)$ & $2.6(5.5)^{a}$ \\
\hline ESRS-GP & $0.9(1.5)$ & $0.6(0.9)$ & $1.1(1.2)$ & $1.7(1.5)^{b}$ & $0.2(2.0)$ & $1.1(1.9)^{a}$ \\
\hline
\end{tabular}

ESRS: the Extrapyramidal Symptom Rating Scale; PANSS, the Positive and Negative Syndrome Scale.

${ }^{a} p<.05$ for the intra-group comparison (paired-t test, two-tailed).

${ }^{b} p<.05$ for the comparison between risperidone group and haloperidol group (t-test, two-tailed). 
Table 3. Continuous Performance Test (CPT) Performance at Baseline and Endpoint of the Two Groups of Schizophrenic Patients

\begin{tabular}{|c|c|c|c|c|c|c|}
\hline \multirow[b]{2}{*}{ CPT index } & \multicolumn{2}{|c|}{ Baseline } & \multicolumn{2}{|c|}{ Endpoint } & \multicolumn{2}{|c|}{ Change } \\
\hline & $\begin{array}{c}\text { Risperidone } \\
(\mathrm{n}=19) \\
\text { Mean (SD) }\end{array}$ & $\begin{array}{l}\text { Haloperidol } \\
(\mathrm{n}=19) \\
\text { Mean (SD) }\end{array}$ & $\begin{array}{c}\text { Risperidone } \\
(\mathrm{n}=19) \\
\text { Mean (SD) }\end{array}$ & $\begin{array}{c}\text { Haloperidol } \\
(\mathrm{n}=19) \\
\text { Mean (SD) }\end{array}$ & $\begin{array}{c}\text { Risperidone } \\
(\mathrm{n}=19) \\
\text { Mean (SD) }\end{array}$ & $\begin{array}{c}\text { Haloperidol } \\
(\mathrm{n}=19) \\
\text { Mean (SD) }\end{array}$ \\
\hline \multicolumn{7}{|l|}{ Undegraded } \\
\hline Hit rate & $0.65(0.33)$ & $0.56(0.34)$ & $0.73(0.29)$ & $0.57(0.35)$ & $0.08(0.33)$ & $0.01(0.45)$ \\
\hline False alarm rate & $0.03(0.04)$ & $0.06(0.09)$ & $0.01(0.02)$ & $0.04(0.05)$ & $-0.01(0.04)$ & $-0.02(0.09)$ \\
\hline $\mathrm{d}^{\prime}$ & $2.74(1.70)$ & $1.97(1.85)$ & $3.26(1.35)$ & $2.15(1.90)^{a}$ & $0.52(1.50)$ & $0.18(2.29)$ \\
\hline $\ln \beta$ & $1.94(1.48)$ & $1.20(1.93)^{a}$ & $2.12(0.96)$ & $1.38(2.09)$ & $0.18(1.33)$ & $0.19(2.35)$ \\
\hline Adjusted z score of $\mathrm{d}^{\prime}$ & $-2.27(2.39)$ & $-3.24(2.68)$ & $-1.53(1.86)$ & $-2.98(2.55)^{a}$ & $0.74(2.13)$ & $0.26(3.25)$ \\
\hline \multicolumn{7}{|l|}{$25 \%$ degraded } \\
\hline Hit rate & $0.50(0.31)$ & $0.40(0.31)$ & $0.47(0.32)$ & $0.39(0.33)$ & $-0.03(0.33)$ & $-0.04(0.35)$ \\
\hline False alarm rate & $0.03(0.02)$ & $0.04(0.07)$ & $0.03(0.02)$ & $0.04(0.03)$ & $-0.003(0.02)$ & $-0.005(0.06)$ \\
\hline $\mathrm{d}^{\prime}$ & $1.97(1.39)$ & $1.54(1.69)$ & $1.82(1.54)$ & $1.55(1.68)$ & $-0.15(1.55)$ & $-0.13(1.86)$ \\
\hline $\ln \beta$ & $1.62(1.71)$ & $1.32(1.68)$ & $1.51(1.90)$ & $1.32(1.67)$ & $-0.11(1.60)$ & $-0.17(2.26)$ \\
\hline Adjusted z score of $\mathrm{d}^{\prime}$ & $-3.29(2.05)$ & $-3.83(2.40)$ & $-3.50(2.13)$ & $-3.83(2.37)$ & $-0.21(2.21)$ & $-0.18(2.64)$ \\
\hline
\end{tabular}

Adjusted z score of $\mathrm{d}^{\prime}$ was derived from standardization with adjustment for age, sex, and education on the basis of the CPT scores of 345 community adults. All within-group comparisons between baseline and endpoint are not statistically significant at .05 level (two-tailed).

${ }^{a} p<0.05$ for the comparison between risperidone group and haloperidol group (t-test, two-tailed)

1992). Furthermore, our results showed that the atypical neuroleptic risperidone did not improve patients' CPT performance. This finding is similar to those of studies that used traditional neuroleptics, and is consistent with a previous study of the effects of clozapine on cognition (Goldberg et al. 1993).

Despite the equivalence in CPT performance at baseline and no significant change from baseline to endpoint for both the risperidone and haloperidol groups, the undegraded CPT $\mathrm{d}^{\prime}$ of the risperidone group was better than that of the haloperidol group. However, the two groups did not differ at endpoint in the degraded CPT d', which is more difficult than the undegraded one. Similarly, although patients' baseline $\mathrm{d}^{\prime}$ tended to be associated with their proportional change in $\mathrm{d}^{\prime}\left(\Delta \mathrm{d}^{\prime}\right)$ for the undegraded CPT, the association was negligible for the degraded one. These two phenomena might be explained by the observation that in a population with decreased attentional resources, the increased processing demands simply exceed its subjects' processing ability (Seidman et al.1998). This highlights another important factor that might influence the evaluation of the effect of neuroleptics on CPT performance: the format of the CPT. Of the three studies that used the simple $X$ version of the CPT (Erickson et al. 1984; Orzack et al. 1967; Spohn et al. 1977), only one of them failed to detect significant change in performance, probably because of small sample sizes $(n=11)$. The authors also attributed their failure to detect change in performance partly to the immature attentional mechanism of their adolescent samples (Erickson et al. 1984). Another study using the CPT-X increased the perceptual loads by degrading the stimuli and reported a significant difference in patients' performance assessed during active psychotic state and that assessed during remission state (Nuechterlein et al. 1991). When a working memory component was added to the task, as in the case of CPTAX used in Nuechterlein et al. (1991) and another two studies (Epstein et al. 1996; Finkelstein et al. 1997) as well as the undegraded CPT in this study, and the case of CPT-Identical Pairs used in Cornblatt et al. (1997), no changes in CPT performance were noted. Because the degraded session used in this study included not only a sensory-perceptual component but also a working memory component, it may make the task more effortful than the Degraded Stimulus CPT used in Nuechterlein et al. (1991). This might explain why we did not find any improvement in performance on the degraded 1-9 CPT in this study. Overall, these findings indicate that the various CPT versions might relate to different components of sustained attention: the more difficult ones are stable vulnerability indicators, while the simpler ones might be mediating vulnerability indicators.

The potential confounding effect of psychiatric symptoms and EPS on CPT performance was controlled for in this study in three ways. First, unlike the first study by Epstein et al. (1996), in which there was no significant difference in clinical symptoms between two time points, there were significant reductions in psychiatric symptoms at endpoint in our study. The difference in changes in clinical symptoms in these two studies might be accounted for by the fact that the present study recruited patients with prominent psychopathology (as indicated by their PANSS scores) and were relatively early in their phase of disease (mean duration of illness $=7.8 \pm 6.8$ years), while Epstein et al. (1996) reported on patients with chronic illness (mean 
duration of illness $=20 \pm 9$ years). Thus, the lack of effect of both risperidone and haloperidol on CPT performance in this study could not be attributed to absence of improvement in clinical symptoms. Second, risperidone causes less severe EPS than haloperidol, as revealed by the absence of change of ESRS-P scores at the end of the study in the risperidone group. The lack of effect of risperidone on CPT performance is therefore not likely to be due to interference from EPS. Third, the regression analyses of CPT indexes on treatment group and scores of PANSS subscales and ESRS-P did not reveal any significant effect of coexisting symptoms.

It is intriguing to compare the findings in this study to those in recent basic studies on the influences of various neurotransmitter systems on CPT performance. In rats, although motor-slowing itself has been shown to have no effect on choice accuracy, anticholinergic agents and $\alpha-2$ adrenergic agonist have been reported to decrease hit rate in attention tasks (Bushnell et al. 1997). Lesions that depleted cortical cholinergic input in rats also lead to impairment in discrimination in sustained attention performance (McGaughy and Sarter 1998). However, when co-administered with chronic haloperidol, anticholinergic agents have been reported to reverse the haloperidol-induced elevations in errors of omission in experimental animals and improve motor function manifested as shortened reaction time (Brockel and Fowler 1995), at the expense of cognitive impairment, mainly memory impairment (Bymaster et al. 1993). However, in human subjects, although level of serum anticholinergicity can distinguish between patients who received clozapine and those who received risperidone, it does not affect general cognitive functions (Tracy et al. 1998). An important implication of these studies is that the adjuvant medications frequently used in combination with neuroleptics might affect CPT performance itself. In this study we have made efforts to withdraw all adjuvant medications one day prior to the CPT evaluation at endpoint to prevent short-term confounding effects. However, one must bear in mind that such a maneuver might not be sufficient to reverse the long-term modulation of the neurotransmitter systems by these centrally acting agents. Nevertheless, since the separate analysis on a subgroup of patients who received risperidone without any adjuvant medication throughout the study still showed that the CPT indexes remained virtually unchanged, at least the finding that sustained attention deficits in schizophrenic patients are not amendable by risperidone is unlikel to be confounded by adjuvant medications.

Thus, our results suggest that CPT performance deficits are independent of changes in clinical symptoms and might be stable vulnerability indicators of schizophrenia. Alternatively, these findings might imply that biochemical mechanisms other than combined dopamine-serotonin antagonism are contributing to the sus- tained attention deficits in schizophrenia. However, it should be borne in mind that, although the sample size of this study was comparable to those of most previous studies, it nonetheless was small. In addition, the washout period might not have been long enough to eliminate the effects of previous antipsychotic medications, which may have obscured the true differences between the effects of the two neuroleptics. In this regard, the results should be interpreted cautiously. Further studies concentrating on the different $\mathrm{CPT}$ versions with detailed analysis of their components might shed some light on the nature of attentional mechanisms and their relationships with antipsychotic medications.

\section{REFERENCES}

Addington J, Addington D (1997): Neurocognitive functioning in schizophrenia: A trial of risperidone versus haloperidol. Can J Psychiatry 42: 983

American Psychiatric Association (1987): Diagnostic and Statistical Manual of Mental Disorders (Third Edition, Revised). Washington, DC, APA

Asarnow RF, MacCrimmon DJ (1978): Residual performance deficit in clinically remitted schizophrenics: A marker of schizophrenia? J Abnorm Psychol 87:597-608

Brockel BJ, Fowler SC (1995): Effects of chronic haloperidol on reaction time and errors in a sustained attention task: Partial reversal by anticholinergics and by amphetamine. J Pharmacol Exp Ther 275:1090-1098

Bushnell PJ, Oshiro WM, Padnos BK (1997): Detection of visual signals by rats: Effects of chlordiazepoxide and cholinergic and adrenergic drugs on sustained attention. Psychopharmacol. 134:230-241

Bymaster FP, Heath I, Hendrix JC, Shannon HE (1993): Comparative behavioral and neurochemical activities of cholinergic antagonists in rats. J Pharmacol Exp Ther 267:16-24

Carman J, Peuskens J, Vangeneugden A (1995): Risperidone in the treatment of negative symptoms of schizophrenia: A meta-analysis. Int Clin Psychopharmacol 10:207213

Chen WJ, Hsiao CK, Hsiao L-L, Hwu H-G (1998a): Performance of the Continuous Performance Test among community samples. Schizophr Bull 24:163-174

Chen WJ, Liu SK, Chang C-J, Lien Y-J, Chang Y-H, Hwu H-G (1998b): Sustained attention deficit and schizotypal personality features in nonpsychotic relatives of schizophrenic patients. Am J Psychiatry 155:1214-1220

Cheng JJ, Ho H, Chang CJ, Lan SY, Hwu HG (1996): Positive and Negative Syndrome Scale (PANSS): Establishment and reliability study of a Mandarin Chinese language version. Chinese Psychiatry 10:251-258

Chouinard G, Ross-Chouinard A, Annable L, Jones BD (1980): The Extrapyramidal Symptom Rating Scale. Can J Neurol Sci 7:233

Cornblatt BA, Lenzenweger MF, Erlenmeyer-Kimling L (1989): The Continuous Performance Test, identical pairs version: II. Contrasting attentional profiles in 
schizophrenic and depressed patients. Psychiatry Res 29:65-85

Cornblatt BA, Keilp JG (1994): Impaired attention, genetics, and the pathophysiology of schizophrenia. Schizophr Bull 20:31-46

Cornblatt BA, Obuchowski M, Schnur DB, O'Brien JD (1997): Attention and clinical symptoms in schizophrenia. Psychiatr Quart 20:31-46

Earle-Boyer EA, Serper MR, Davidson M, Harvey PD (1991): Continuous performance tests in schizophrenic patients: Stimulus and medication effects on performance. Psychiatry Res 37:47-56

Epstein JI, Keefe RSE, Roitman SL, Harvey PD, Mohs RC (1996): Impact of neuroleptic medications on continuous performance test measures in schizophrenia. Biol Psychiatry 39:902-905

Erickson WD, Yellin AM, Hopwood JH, Realmuto GM, Greenberg LM (1984): The effects of neuroleptics on attention in adolescent schizophrenics. Biol Psychiatry 19:745-753

Finkelstein JRJ, Cannon TD, Gur RE, Gur RC, Moberg P (1997): Attentional dysfunctions in neuroleptic-naive and neuroleptic-withdrawn schizophrenic patients and their siblings. J Abnorm Psychol 106:203-212

Goldberg TE, Greenberg RD, Griffin SJ, Gold JM, Kleinman JE, Pickar D, Schulz SC, Weinberg DR (1993): The effect of clozapine on cognition and psychiatric symptoms in patients with schizophrenia. Br J Psychiatry 162:43-48

Harvey PD, Keefe RS, Moskowitz J, Putnam KM, Mohs RC, Davis KL (1990): Attentional markers of vulnerability to schizophrenia: Performance of medicated and unmedicated patients and normals. Psychiatry Res 33:179-188

Harvey PD, Keefe RSE, Mitroupolou V, Dupre R, Roitman SL, Mohs RC, Siever LJ (1996): Information-processing markers of vulnerability to schizophrenia: Performance of patients with schizotypal and nonschizotypal personality disorders. Psychiatry Res 60:49-56

Kay SR, Fiszbein A, Opler LA (1987): The positive and negative syndrome scale (PANSS) for schizophrenia. Schizophr Bull 13:261-276

Kay SR (1991): Positive and Negative Syndromes in Schizophrenia: Assessment and Research. New York, Brunner/Mazel

Lenzenweger MF, Cornblatt BA, Putnick M (1991): Schizotypy and sustained attention. J Abnorm Psychol 100:84-89

Leysen JE, Janssen PMF, Megens AAHP, Schotte A (1994): Risperidone: A novel antipsychotic with balanced serotonin-dopamine antagonism, receptor occupancy profile, and pharmacologic activity. J Clin Psychiatry 55:5-12

Liu SK, Chang C-J, Lin H-N (1996): A double-blind study of risperidone versus haloperidol treatment in acute schizophrenic patients. Chinese Psychiatry 10:365-376 (in Chinese)

Liu SK, Hwu H-G, Chen WJ (1997): Clinical symptom dimensions and deficits on the Continuous Performance Test in schizophrenia. Schizophr Res 25:211-219

McGaughy J, Sarter M (1998): Sustained attention performance in rats with intracortical infusions of 192 IgG- saporin-induced cortical cholinergic deafferentation: Effects of Physostigmine and FG 7142. Behav Neurosci 112:1519-1525

Mirsky AF, Delisi LE, Buchsbaum MS, Quinn OW, Schwerdt P, Siever LJ, Mann L, Weingartner H, Zec R, Sostek A, Alterman I, Revere V, Dawson SD, Zahn TP (1984): The Genain Quadruplets: Psychological studies. Psychiatry Res 13:77-93

Mirsky AF, Yardley SL, Jones BP, Walsh D, Kendler KS (1995): Analysis of the attention deficit in schizophrenia: A study of patients and their relatives in Ireland. J Psychiatr Res 29:23-42

Mussgay L, Hertwig R (1990): Signal detection indices in schizophrenics on a visual, auditory and bimodal Continuous Performance Test. Schizophr Res 3:303-310

Nestor PG, Faux SF, McCarley RW, Sands SF, Horvath TB, Peterson A (1991): Neuroleptics improve sustained attention in schizophrenia: A study using signal detection theory. Neuropsychopharmacol 4:145149

Norusis MJ (1986): The Statistical Package for Social Sciences (SPSS), Manual of Reference. Chicago, SPSS, Inc.

Nuechterlein KH, Dawson ME (1984): A heuristic vulnerability/stress model of schizophrenic episodes. Schizophr Bull 10:300-312

Nuechterlein KH (1991): Vigilance in schizophrenia and related disorders. In Steinhauer SR, Gruzelier JH, Zubin J (eds), Handbook of Schizophrenia, Vol. 5: Neuropsychology, Psychophysiology and Information Processing. Amsterdam, Elsevier, pp 397-433

Nuechterlein KH, Dawson ME, Ventura J, Fogelson D, Gitlin M, Mintz J (1991): Testing vulnerability models: Stability of potential vulnerability indicators across clinical state. In Häfner H, Gattaz WF (eds), Search for the Causes of Schizophrenia, Vol.II. Berlin, SpringerVerlag, pp 177-191

Nuechterlein KH, Dawson ME, Gitlin M, Ventura J, Goldstein MJ, Snyder KS, Yee CM, Mintz J (1992): Developmental processes in schizophrenic disorders: Longitudinal studies of vulnerability and stress. Schizophr Bull 18:387-425

Nurnberger JI Jr., Blehar MC, Kaufmann CA, York-Cooler C, Simpson SG, Harkavy- Friedman J, Severe JB, Malaspina D, Reich T, collaborators from the NIMH Genetics Initiative (1994): Diagnostic Interview for Genetic Studies: Rationale, unique features, and training. Arch Gen Psychiatry 51:849-859

Orzack MH, Kornetsky C (1966): Attention dysfunction in chronic schizophrenia. Arch Gen Psychiatry 14:323-327

Orzack MH, Kornetsky C, Freeman H (1967): The effect of daily carphenazine on attention in the schizophrenic patient. Psychopharmacologia 8:31-38

Orzack MH, Kornetsky C (1971): Environmental and familial predictors of attention behavior in chronic schizophrenics. J Psychiatr Res 9:21-29

Peuskens J (1995): Risperidone in the treatment of patients with chronic schizophrenia: A multi-national, multicentre, double-blind, parallel-group study versus haloperidol. Br J Psychiatry 166:712-726

Rossi A, Mancini F, Stratta P, Mattei P, Gismondi R, Pozzi F, Casacchia M (1997): Risperidone, negative 
symptoms and cognitive deficit in schizophrenia: An open study. Acta Psychiatr Scand 95:40-43

Rosvold HE, Mirsky AF, Sarason I, Bransome ED Jr., Beck LH (1956): A Continuous Performance Test of brain damage. J Consult Psychol 20:343-350

Rutschmann J, Cornblatt B, Erlenmeyer-Kimling L (1977): Sustained attention in children at risk for schizophrenia: Report on a Continuous Performance Test. Arch Gen Psychiatry 34:571-575

Seidman LJ, Van Manen KJ, Turner WM, Gamser DM, Faraone SV, Goldstein JM, Tsuang MT (1998): The effects of increasing resource demand on vigilance performance in adults with schizophrenia or developmental attentional/learning disorders: A preliminary study. Schizophr Res 34:101-112

Serper MR, Bergman RL, Harvey PD (1990): Medication may be required for the development of automatic information processing in schizophrenia. Psychiatry Res 32:281-288

Spohn HE, Lacoursiere RB, Thompson K, Coyne L (1977): Phenothiazine effects on psychological and psychophysiological dysfunction in chronic schizophrenics. Arch Gen Psychiatry 34:633-644
Strandburg RJ, Marsh JT, Brown WS, Asarnow RF, Guthrie D, Higa J (1990): Event- related potential correlates of impaired attention in schizophrenic children. Biol Psychiatry 27:1103-1115

Tracy JL, Monaco CA, Abraham G, Josiassen RC, Pollock BG (1998): Relation of serum anticholinergicity to cognitive status in schizophrenia patients taking clozapine or risperidone. J Clin Psychiatry. 59:184188

Van Cauteren H, Megens AHPA, Lampo A, Meuldermans W (1996): Risperidone: An overview of animal pharmacology, toxicology and pharmacokinetics. In Kane JM, Moller H-J, Awouters F (eds), Serotonin in Antipsychotic Treatment: Mechanisms and Clinical Practice. New York, Marcel Dekker, pp 253-276

Walker E, Shaye J (1982): Familial schizophrenia: A predictor of neuromotor and attentional abnormalities in schizophrenia. Arch Gen Psychiatry 39:1153-1156

Wohlberg GW, Kornetsky C (1973): Sustained attention in remitted schizophrenics. Arch Gen Psychiatry 28:533537 